\title{
Crescimento e conteúdo de frutanos em plantas de Vernonia herbacea (Vell.) Rusby submetidas à adubação nitrogenada
}

\author{
GERALDO R.F. CUZZUOL ${ }^{1}$, MARIA ANGELA M. CARVALHO², \\ CLAUDIO J. BARBEDO ${ }^{2}$ e LILIAN B.P. ZAIDAN ${ }^{2,3}$
}

(recebido: 29 de maio de 2002; aceito: 1 de janeiro de 2003)

\begin{abstract}
Growth and fructan contents in plants of Vernonia herbacea (Vell.) Rusby cultivated under nitrogen supply). Plants of $V$. herbacea accumulate high amounts of fructans of the inulin type in the underground organs, named rhizophores. The effect of different concentrations of nitrogen, 6,12 and $24 \mathrm{~kg} \mathrm{~N}$.ha ${ }^{-1}$ supplied as $\left(\mathrm{NH}_{4}\right)_{2} \mathrm{SO}_{4}$ on plant growth and fructan accumulation was investigated in plants obtained from rhizophore fragments and cultivated in a cerrado area. Young, six-month-old plants, showed lower amounts of fructans and increases in height, leaf area, dry mass of the aerial organs and rhizophores with increasing concentrations of nitrogen. After 12 months, growth was estimulated only in plants receiving 6 to $12 \mathrm{~kg} \mathrm{~N} . \mathrm{ha}^{-1}$. The data showed that in young plants fructan content is negatively correlated to growth and to increasing nitrogen concentrations. On the contrary, plants with 12 months treated with $24 \mathrm{~kg} \mathrm{~N} . \mathrm{ha}^{-1}$ accumulated $6.0 \mathrm{~g}$ fructan per plant while in control plants, not treated with supplementary N, this value was only $3.5 \mathrm{~g}$. These results indicate that the $24 \mathrm{~kg} \mathrm{~N} \mathrm{Na}^{-1}$ concentration is recomended for fructan production in plants with 12 months.
\end{abstract}

Key words - Asteraceae, cerrado, fructan, inulin, plant growth

RESUMO - (Crescimento e conteúdo de frutanos em plantas de Vernonia herbacea (Vell.) Rusby submetidas à adubação nitrogenada). Vernonia herbacea acumula altas concentrações de frutanos do tipo inulina em seus órgãos subterrâneos de reserva, denominados rizóforos. Foi estudada a influência da adubação nitrogenada no crescimento dessa espécie e na produção de frutanos. Plantas obtidas a partir de fragmentos de rizóforos foram cultivadas em área de cerrado onde receberam três doses de nitrogênio: 6, 12 e $24 \mathrm{~kg} \mathrm{~N}$.ha-1 na forma de $\left(\mathrm{NH}_{4}\right)_{2} \mathrm{SO}_{4}$. Plantas jovens, com seis meses de idade, mostraram aumento em altura, área foliar e massa seca da parte aérea e dos rizóforos em resposta ao aumento da dose de nitrogênio. Por outro lado, o teor de frutanos decresceu com o aumento da concentração do nitrogênio. Após doze meses de cultivo, o crescimento das plantas foi estimulado apenas nas doses entre 6 e $12 \mathrm{~kg} \cdot \mathrm{ha}^{-1}$ de nitrogênio. Os resultados mostraram, também, que o teor de frutanos em plantas jovens está correlacionado negativamente tanto ao crescimento quanto às concentrações crescentes de nitrogênio. Já as plantas tratadas com $24 \mathrm{~kg} \mathrm{~N} \cdot \mathrm{ha}^{-1}$ chegaram a acumular $6,0 \mathrm{~g}$ de frutanos por planta, enquanto nas plantas controle, que não receberam N suplementar, esse valor foi de 3,5 g. Assim, aplicação de $24 \mathrm{~kg}$ N.ha ${ }^{-1}$ é recomendada para uma colheita antecipada (12 meses) visando à produção de frutanos.

Palavras-chave - Asteraceae, cerrado, frutano, inulina, crescimento vegetal

\section{Introdução}

A baixa fertilidade e a deficiência hídrica do solo encontram-se entre os principais fatores limitantes da produtividade vegetal (Haridasan et al. 1997). Estudos sobre fertilidade do solo são amplamente documentados para espécies cultivadas (Marschner 1995), porém são escassas as informações a respeito das exigências nutricionais de espécies nativas, em especial as do cerrado.

\footnotetext{
1. Universidade Federal do Espírito Santo, Departamento de Biologia, 29060-900 Vitória, ES, Brasil.

2. Instituto de Botânica, Caixa Postal 4005, 01061-970 São Paulo, SP, Brasil.

3._Autor para correspondência: lilianzaidan@uol.com.br
}

Os trabalhos sobre fertilização mineral em espécies nativas do cerrado foram realizados, principalmente, com arbóreas e em poucas espécies do estrato herbáceo. De modo geral, esses estudos mostraram que a maioria das espécies respondeu à aplicação de cálcio e de adubação, aumentando a absorção dos nutrientes (Moraes 1994, Vilela \& Haridasan 1994, Haridasan et al. 1997). Fornecendo diferentes macronutrientes, Melo (1999) demonstrou que o fósforo foi o nutriente mais limitante para algumas arbóreas na fase de muda, proporcionando maior crescimento e produção de matéria seca. Esse autor concluiu ainda que, apesar de adaptadas à baixa fertilidade, as espécies nativas são capazes de absorver mais nutrientes desde que haja maior disponibilidade destes no solo, mostrando que a escassez de nutrientes no solo é um fator limitante para as espécies nativas do cerrado. 
O comportamento nutricional de gramíneas e outras herbáceas do cerrado sensu stricto mostrou que estas também são bem adaptadas aos solos oligotróficos e ácidos do cerrado (Vilela \& Haridasan 1994). No entanto, o fato dessa vegetação ser tolerante à baixa fertilidade não elimina a possibilidade de se obter respostas à maior disponibilidade de nutrientes do solo (Vilela \& Haridasan 1994). Esta hipótese foi confirmada por Haridasan et al. (1997) ao demonstrarem que herbáceas do cerrado das famílias Asteraceae, Poaceae, Euphorbiacea, Proteaceae e Sapindaceae absorvem mais $\mathrm{Ca}, \mathrm{N}, \mathrm{P}$ e K em resposta ao aumento da aplicação de cálcio e da adubação no solo. Contudo, nenhuma análise de crescimento foi realizada com os membros dessas famílias. Teixeira et al. (1997), estudando Vernonia herbacea, uma Asteraceae perene, nativa do estrato herbáceo do cerrado, mostraram que sob condições controladas em casa de vegetação, a solução nutritiva de Hoagland promoveu o crescimento dos órgãos aéreos.

Plantas de $V$. herbacea possuem órgãos-dreno subterrâneos, denominados rizóforos, que acumulam frutanos do tipo inulina (Carvalho \& Dietrich 1993) que são polímeros de frutose originados da sacarose e que apresentam ligações $\beta-2,1$ entre os resíduos de frutose (Pollock et al. 1996). Essa classe de carboidratos parece estar relacionada a mecanismos de osmorregulação em plantas que passam por períodos de restrição de água e/ou baixas temperaturas em determinadas épocas do ano (Pollock \& Jones 1986).

Variações sazonais no conteúdo e na composição de frutanos têm sido relatadas para diversas espécies, incluindo Helianthus tuberosus (Bacon \& Loxley 1952), Cichorium intybus (Bhatia et al. 1974) e forrageiras e cereais (Pollock \& Cairns 1991) de regiões temperadas e para algumas espécies tropicais do cerrado, como Viguiera discolor (Isejima \& Figueiredo-Ribeiro 1993), Gomphrena macrocephala (Vieira \& FigueiredoRibeiro 1993) e Vernonia herbacea (Carvalho \& Dietrich 1993). No inverno, quando as partes aéreas das plantas de $V$. herbacea senescem, o conteúdo de inulina aumenta, chegando a representar $80 \%$ da massa seca dos seus rizóforos. O ciclo fenológico dessa espécie é caracterizado por uma fase de crescimento vegetativo que se inicia na primavera e se estende até o final do outono, quando os órgãos aéreos entram em senescência e os rizóforos, em dormência. Na primavera do ciclo de vida subsequente, ocorre a brotação das gemas vegetativas dos rizóforos, dando início à fase de crescimento rápido seguido de floração (Carvalho \& Dietrich 1993).
Além da importância ecológica, os frutanos são de grande interesse econômico, devido às suas propriedades benéficas à saúde (Tomomatsu 1994) que despertaram a atenção da indústria mundial de alimentos. Essa classe de carboidratos tem sido empregada com sucesso nos casos de constipação, prevenção de doenças do intestino, por estimular a proliferação das bifidobactérias, e no controle da osteoporose, por estimular a absorção de cálcio (Coussement \& Franck 1998). O fato dos frutanos não serem absorvidos pelo organismo humano (Nilsson et al. 1988, Hidaka \& Hirayama 1991) fez desses polímeros de frutose um adoçante alternativo de baixo teor calórico.

As maiores fontes comerciais de inulina são raízes de Dhalia sp. e de C. intybus e tubérculos de H. tuberosus, todas da família Asteraceae e de regiões temperadas. Dentre essas espécies, $C$. intybus é a mais produtiva, podendo atingir 12 t.ha ${ }^{-1}$ de inulina (Meijer et al. 1993). A produção de frutanos em $V$. herbacea foi estimada em 0,522 t.ha-1 após dois anos de cultivo (Carvalho et al. 1998). Esses autores verificaram que a aplicação em dose única de N, P e K não promoveu o aumento da biomassa de rizóforos, nem da produção de frutanos. Contudo, o efeito da adubação nitrogenada em cobertura ainda não foi estudado.

Considerando que essa espécie acumula elevadas concentrações de frutanos em seus órgãos de reserva e em vista do crescente interesse por novas fontes de frutanos para uso na indústria alimentícia e farmacêutica, $V$. herbacea figura como alternativa para o uso sustentável do cerrado. Portanto, o presente trabalho foi realizado com o objetivo de estimular a produtividade de inulina com o fornecimento diferencial de nitrogênio para as plantas.

\section{Material e métodos}

Material biológico e delineamento experimental - Plantas de Vernonia herbacea (Vell.) Rusby obtidas por multiplicação vegetativa, a partir de fragmentos de rizóforos medindo aproximadamente $4 \mathrm{~cm}$ de comprimento, foram cultivadas entre abril de 1997 e abril de 1998 na Reserva Biológica e Estação Experimental de Moji-Guaçu ( $22^{\circ} 35^{\prime}$ S e $47^{\circ} 44^{\prime}$ W), uma área de cerrado do estado de São Paulo.

O delineamento experimental utilizado foi o de blocos ao acaso, com seis repetições, quatro tratamentos e 54 plantas por parcela, no espaçamento de $25 \mathrm{~cm}$ entre plantas e $50 \mathrm{~cm}$ entre linhas. Os dados da análise química da camada de $20 \mathrm{~cm}$ do solo do local do experimento são apresentados na tabela 1 . Os resultados da análise química do solo, realizada no Laboratório de Fertilidade do Solo, da Faculdade de Ciências 
Tabela 1. Composição química do solo do cerrado da Reserva Biológica e Estação Experimental de Moji-Guaçu. As análises foram realizadas no Laboratório de Fertilidade do Solo, Faculdade de Ciências Agronômicas (UNESP), Botucatu, SP. M.O. = matéria orgânica; $\mathrm{H}+\mathrm{AL}^{3+}=$ potencial de acidez; $\mathrm{SB}=$ soma das bases; $\mathrm{CTC}=$ capacidade de troca catiônica $=\mathrm{SB}+\left(\mathrm{H}+\mathrm{AL}{ }^{3+}\right) ; \mathrm{V}=$ saturação de bases $=(\mathrm{SB} / \mathrm{CTC}) \times 100$.

Table 1. Chemical components of the cerrado soil of the Reserva Biológica e Estação Experimental de Moji Guaçu. The analyses were performed by the Laboratório de Fertilidade do Solo, Faculdade de Ciências Agronômicas (UNESP), Botucatu, SP.

\begin{tabular}{|c|c|c|c|c|c|c|c|c|c|}
\hline $\mathrm{P}_{\text {resina }}$ & M.O. & $\mathrm{pH}$ & $\mathrm{K}^{+}$ & $\mathrm{Ca}^{2+}$ & $\mathrm{Mg}^{2+}$ & $\mathrm{H}+\mathrm{Al}^{3+}$ & SB & CTC & \multirow{3}{*}{$\begin{array}{l}\mathrm{V} \\
\% \\
54\end{array}$} \\
\hline $\mathrm{mg} \mathrm{dm}^{-3}$ & $\mathrm{~g} \mathrm{dm}^{-3}$ & $\mathrm{CaCl}_{2}$ & \multicolumn{6}{|c|}{$\mathrm{mmol}_{\mathrm{c}} \mathrm{dm}^{-3}$} & \\
\hline 1,6 & 10 & 5,8 & 0,2 & 15 & 8 & 21 & 25 & 46 & \\
\hline
\end{tabular}

Agronômicas (UNESP), em Botucatu, SP (tabela 1), indicaram teor muito baixo de $\mathrm{P}$, baixo teor de matéria orgânica (M.O.), baixa acidez $(\mathrm{pH}=5,8)$, teor muito baixo de $\mathrm{K}$, alto teor de $\mathrm{Ca}$ e baixo de $\mathrm{Mg}$ e alto de $\mathrm{Al}$ trocável. $\mathrm{O}$ solo apresentou baixa capacidade de troca cationica (CTC), e extremamente baixa saturação de bases (V).

Para a correção da acidez do solo, foi feita calagem com

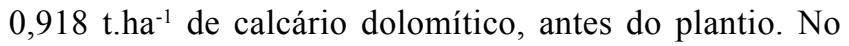
momento do plantio, a adubação básica para todos os tratamentos foi de $20 \mathrm{~kg} \mathrm{ha}^{-1}$ de nitrogênio na forma de sulfato de amônia $\left(\left(\mathrm{NH}_{4}\right)_{2} \mathrm{SO}_{4}\right), 40 \mathrm{~kg} \cdot \mathrm{ha}^{-1}$ de fósforo $\left(\mathrm{P}_{2} \mathrm{O}_{5}\right)$ na forma de termofosfato e $120 \mathrm{~kg} \cdot \mathrm{ha}^{-1}$ de potássio $\left(\mathrm{K}_{2} \mathrm{O}\right)$ na forma de cloreto de potássio. Também foram fornecidos três níveis de nitrogênio: 6, 12 e $24 \mathrm{~kg} \mathrm{~N} \cdot \mathrm{ha}^{-1}$ na forma de $\left(\mathrm{NH}_{4}\right)_{2} \mathrm{SO}_{4} \mathrm{em}$ setembro e dezembro de 1997, respectivamente aos cinco e oito meses do plantio. Os fertilizantes foram aplicados a uma distância de $5 \mathrm{~cm}$ do sulco de plantio e a uma profundidade de $7 \mathrm{~cm}$. A irrigação artificial foi acionada quando necessária. As avaliações para análise de crescimento e do conteúdo de frutanos foram realizadas após seis meses e 12 meses de cultivo.

Análise de crescimento - As medidas de crescimento utilizadas foram altura do maior ramo de cada planta, área foliar e massa seca das partes aérea (caules e folhas) e subterrânea (rizóforos). A massa seca foi determinada após secagem em estufa à temperatura de $60^{\circ} \mathrm{C}$ até obter massa constante; para os rizóforos, foram utilizadas quatro amostras de $3 \mathrm{~g}$ de massa fresca extrapolando-se o valor para a massa total dos rizóforos de cada planta. A área de folhas maiores que $5 \mathrm{~cm}$ de comprimento foi calculada através do programa "Leaf Area \& Analysis" da Skye Instruments Ltd. (1993). Extração de carboidratos solúveis - Os carboidratos solúveis foram extraídos segundo o método utilizado por Carvalho et al. (1998) a partir de seis amostras de rizóforos (1,5 g). As amostras foram fragmentadas e colocadas para ferver em etanol $80 \%$ por 3 minutos para desnaturação enzimática. Em seguida, foram maceradas em gral, aquecidas em banho-maria a $80{ }^{\circ} \mathrm{C}$ por 15 minutos e centrifugadas a 800 g por 10 minutos à temperatura ambiente. $\mathrm{O}$ precipitado foi re-extraído mais duas vezes como descrito anteriormente. Os sobrenadantes foram reunidos, constituindo a fração etanólica composta de fruto-oligossacarídeos, sacarose e monossacarídeos. Os resíduos foram submetidos duas vezes à extração em água destilada a $60{ }^{\circ} \mathrm{C}$ por 30 minutos e os homogeneizados, filtrados à vácuo, em tecido de algodão, para obtenção da fração aquosa contendo os fruto-polissacarídeos. As frações de fruto-oligo e -polissacarídeos foram reunidas, constituindo o extrato de frutanos totais, o qual foi concentrado em rotoevaporador, a $40{ }^{\circ} \mathrm{C}$. Os extratos concentrados foram mantidos a $-20{ }^{\circ} \mathrm{C}$ para posterior análise quantitativa e qualitativa.

Análise dos carboidratos - O conteúdo de frutose livre e combinada presente nos extratos foi estimado pela reação de antrona, modificada para cetoses (Jermyn 1956), usando-se frutose (Sigma) como padrão.

Após deionização em resina catiônica (Dowex-50W, $\mathrm{Na}^{+}$) e aniônica (Dowex-1, $\mathrm{Cl}^{-}$), os carboidratos solúveis neutros foram analisados em coluna de troca aniônica 4×250 mm CarboPac PA-100, utilizando o cromatógrafo de íons Dionex DX-300 acoplado a um detector de pulso amperométrico (HPAEC/PAD). Foi utilizado o gradiente estabelecido por Shiomi (1993). De acordo com este gradiente, o eluente $\mathrm{B}(500 \mathrm{mM}$ acetato de sódio em 150 $\mathrm{mM} \mathrm{NaOH})$, foi adicionado ao eluente A (150 mM NaOH), conforme a seguinte programação: 0-4 $\mathrm{min}, 25 \mathrm{mM}$; 4-25 min, $225 \mathrm{mM}$; 25-35 min, $320 \mathrm{mM}$; 35-39 min, $500 \mathrm{mM}$; 39-41 min, $25 \mathrm{mM}$. O fluxo através da coluna foi de $1 \mathrm{~cm}^{3} \mathrm{~min}^{-1}$ e os potenciais aplicados ao E1(480 ms), E2 (120 ms) e E3 (60 ms) foram de $+0,05,+0,60$ e $-0,60 \mathrm{~V}$, respectivamente. Os padrões de eluição dos componentes das amostras foram comparados com os padrões de fruto-oligo e -polissacarídeos de tubérculos de Helianthus tuberosus.

Análise estatística - Foi aplicada a regressão de polinômios para o estudo da relação entre os parâmetros analisados e as concentrações de $\left(\mathrm{NH}_{4}\right)_{2} \mathrm{SO}_{4}$ e da relação entre crescimento e concentração de frutanos. O erro padrão da média também foi calculado. 


\section{Resultados}

Os resultados obtidos mostraram que a adubação nitrogenada influenciou, significativamente, o crescimento de plantas de $V$. herbacea cultivadas em área de cerrado (figura 1). Em plantas jovens, colhidas aos seis meses, ocorreu aumento na altura, área foliar, massa seca da parte aérea e dos rizóforos em resposta ao aumento da dose de nitrogênio. A dose de 24 $\mathrm{kg} \mathrm{N} . \mathrm{ha}^{-1}$ causou aumento em $50 \%$ na área foliar e na massa seca da parte aérea e dos rizóforos quando comparada às plantas não adubadas (controle). Quanto à altura, essa diferença foi de cerca de $20 \%$. Após doze meses de cultivo, as plantas responderam positivamente às doses entre 6 e $12 \mathrm{~kg} \cdot \mathrm{ha}^{-1}$ de nitrogênio.

Houve diferenças entre as curvas de regressão obtidas para plantas jovens e aos 12 meses (figura 1). Para as primeiras, as curvas foram ascendentes, enquanto para as outras, obteve-se uma regressão

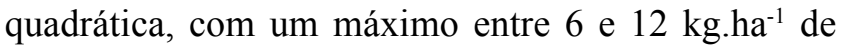
nitrogênio.

Como esperado para plantas em fase de crescimento, a figura 1 mostra, ainda, que aos 12 meses de cultivo, plantas controle e tratadas apresentaram aumento de todas as medidas de crescimento, com valores superiores aos das plantas colhidas aos seis meses.

A razão parte aérea:rizóforos também foi influenciada pela adubação nitrogenada em plantas com 12 meses de idade. Em plantas tratadas com 6 kg.ha ${ }^{-1}$ de nitrogênio, essa razão foi de 0,75 enquanto no controle foi de 0,65 indicando, portanto, promoção de acúmulo de biomassa aérea.

A concentração de frutanos decresceu com o aumento das doses de nitrogênio em plantas jovens (figura 2). Assim, enquanto a concentração de frutanos em plantas que receberam $24 \mathrm{~kg} \mathrm{~N} . \mathrm{ha}^{-1}$ foi de apenas $330 \mathrm{mg} \cdot \mathrm{g}^{-1}$ de massa de matéria seca, esse valor foi de $650 \mathrm{mg} \cdot \mathrm{g}^{-1}$ de massa de matéria seca nas plantas que não receberam a adubação de cobertura, representando uma diferença de 97\%. Em plantas com 12 meses, as diferenças entre os tratamentos também foram acompanhadas por alterações no conteúdo de frutanos. Doses que promoveram maior crescimento ( 6 a $12 \mathrm{~kg} \cdot \mathrm{ha}^{-1}$, figura 1) levaram a um menor acúmulo desses carboidratos de reserva. Por outro lado, a aplicação de $24 \mathrm{~kg}$ ha $^{-1}$ de nitrogênio promoveu acúmulo de frutanos (450 mg. $\mathrm{g}^{-1}$ de massa de matéria seca), representando ganho de $11 \%$ em relação ao valor obtido nas plantas controle $\left(370 \mathrm{mg} \cdot \mathrm{g}^{-1} \mathrm{~ms}\right)$.

Foi observada uma correlação entre os parâmetros

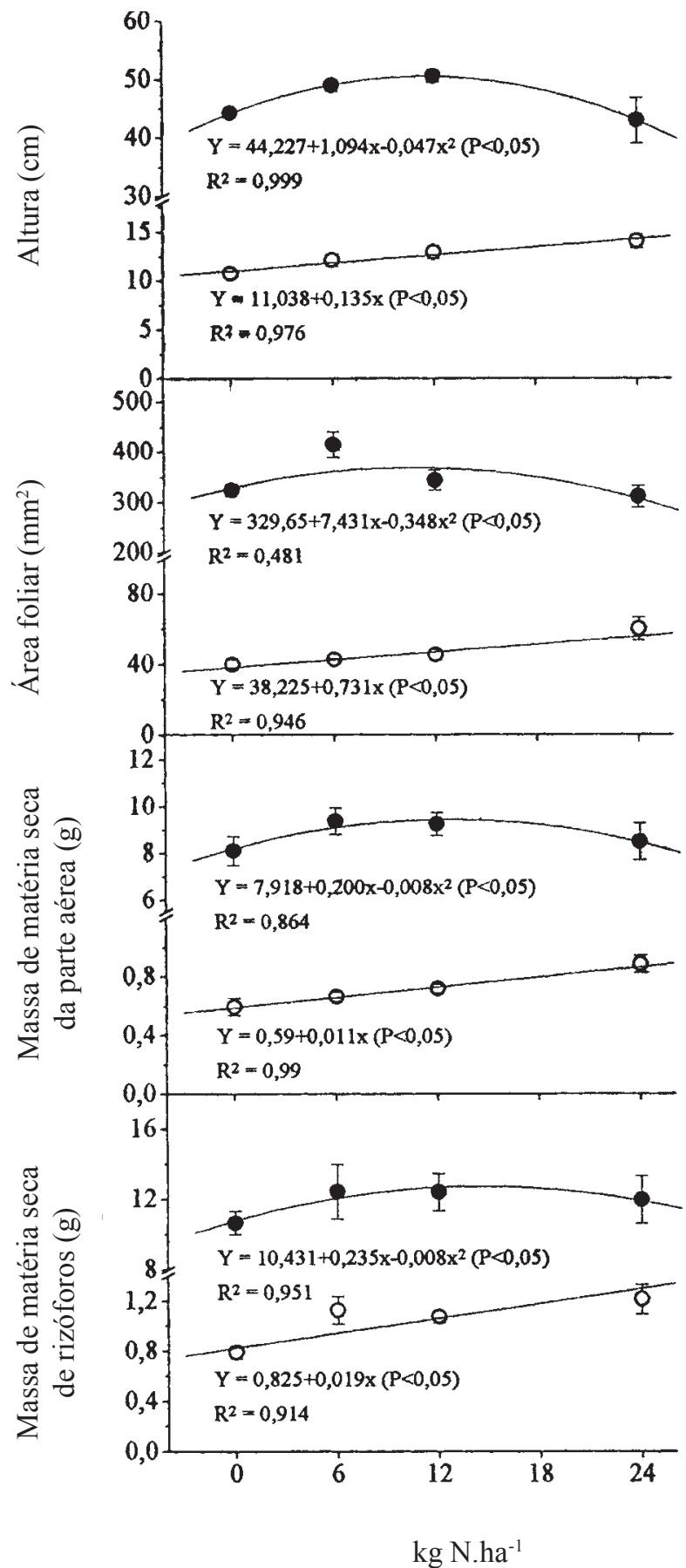

Figura 1. Medidas de altura, área foliar, massa de matéria seca da parte aérea e massa de matéria seca de rizóforos de plantas de Vernonia herbacea cultivadas em diferentes níveis de adubação nitrogenada após 6 meses (○) e 12 meses $(\bullet)$, em uma área de cerrado. Barras representam erro padrão ( $\mathrm{n}$ $=6)$.

Figure 1. Stem height, leaf area, aerial dry mass and rhizophore dry mass of plants of Vernonia herbacea cultivated in a cerrado area, under different nitrogen concentrations for $6(\bigcirc)$ and $12(\bullet)$ months. Bars represent standard error $(n=6)$. 


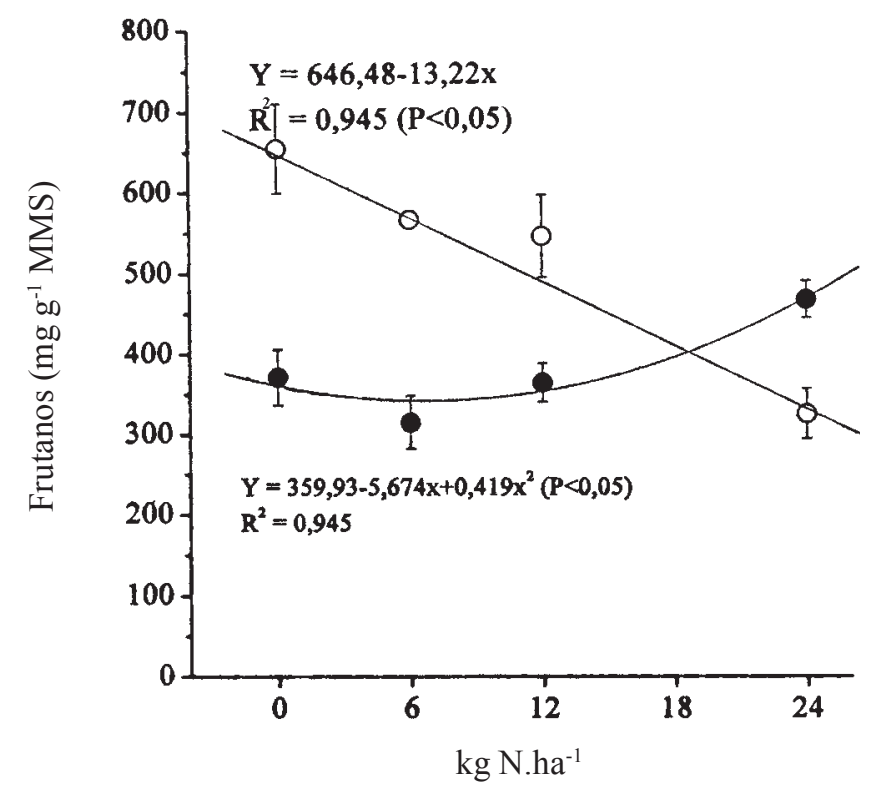

Figura 2. Concentração de frutanos em rizóforos de plantas de Vernonia herbacea cultivadas em diferentes níveis de adubação nitrogenada após 6 meses $(\bigcirc)$ e 12 meses $(\bullet)$, em uma área de cerrado. Barras representam erro padrão $(n=6)$.

Figure 2. Fructan contents in rhizophores of Vernonia herbacea cultivated in a cerrado area, under different nitrogen concentrations for $6(\bigcirc)$ and $12(\bullet)$ months. Bars represent standard error $(n=6)$.

de crescimento e a concentração de frutanos (figura 3) em plantas com seis meses de cultivo. As condições nutricionais favoráveis ao crescimento $\left(24 \mathrm{~kg} \mathrm{~N} . \mathrm{ha}^{-1}\right.$, figura1) levaram ao menor acúmulo de frutanos nos rizóforos (figuras 2, 3). Para plantas colhidas aos 12 meses, nenhuma correlação significativa foi encontrada entre a concentração de frutanos e o crescimento (figura 3). Plantas colhidas aos 6 meses apresentaram concentrações de frutanos próximas de $80 \%$ da massa seca dos rizóforos, exceto quando tratadas com $24 \mathrm{~kg} \mathrm{~N} \cdot \mathrm{ha}^{-1}$.

Os tratamentos de adubação e o tempo de colheita alteraram, também, a produtividade de frutanos (figura 4). Para plantas colhidas aos seis meses, a dose de $6 \mathrm{~kg} \mathrm{~N} \cdot \mathrm{ha}^{-1}$ foi a que promoveu maior produção, com valor estimado de $700 \mathrm{mg}$ de frutanos por planta, correspondendo a um aumento de $40 \%$ em relação ao controle, enquanto em plantas colhidas com 12 meses, a produção de frutanos por planta foi superior, obtendose rendimento máximo de $6 \mathrm{~g}$ por planta com a dose de $24 \mathrm{~kg} \mathrm{~N} \mathrm{ha}^{-1}$. Esse valor corresponde a um aumento de $100 \%$ em relação às plantas não tratadas.
As análises dos frutanos por HPAEC/PAD mostraram que a adubação nitrogenada não alterou o padrão dos componentes da série homóloga de frutanos em plantas colhidas aos seis meses de idade (figura 5), mesmo no tratamento que proporcionou melhor ganho de biomassa ( $\left.24 \mathrm{~kg} \mathrm{~N} . \mathrm{ha}^{-1}\right)$. Já aos 12 meses de cultivo, diferenças ocorreram quando foram adicionados $6 \mathrm{~kg} \cdot \mathrm{ha}^{-1}$ de nitrogênio, podendo ser observada maior proporção de 1-cestose (C), nistose (Nis) e dos frutooligossacarídeos de GP 5-8. Em comparação às plantas jovens, plantas com 12 meses apresentaram maior proporção de frutanos com menor grau de polimerização (GP 5-8) e menor proporção de fruto-polissacarídeos de cadeias longas (GP > 25). Numa análise mais detalhada dos cromatogramas, foram identificados componentes da série de inulo- $n$-ose em maiores proporções nos rizóforos de plantas com 12 meses de cultivo, quando tratadas com 6 a 24 kg N.ha- ${ }^{-1}$. Os picos, sempre muito baixos dessa segunda série de frutanos podem ser visualizados em posição alternada com os picos dos componentes da série principal de frutanos.

\section{Discussão}

De maneira geral, a adubação nitrogenada em plantas de $V$. herbacea cultivadas em área de cerrado resultou em benefício para o crescimento. A intrapolação dos valores da análise de crescimento, segundo as regressões polinomiais obtidas, permite afirmar que a dose ideal de $\mathrm{N}$ para fins de crescimento está entre 10 e $15 \mathrm{~kg} \mathrm{~N} \cdot \mathrm{ha}^{-1}$, pois os pontos máximos das regressões obtidas foram observados com as doses de $11,64,10,68,12,50$ e 14,69 kg N.ha-1, respectivamente para altura, área foliar, massa de matéria seca da parte aérea e massa de matéria seca de rizóforos. Haridasan et al. (1997), analisando seis espécies do estrato herbáceo do cerrado, constataram que $\mathrm{N}, \mathrm{P}, \mathrm{K}$ e $\mathrm{Ca}$ são fatores limitantes para o crescimento desse tipo de vegetação. Assim, como já mencionado, embora as espécies herbáceas do cerrado estejam bem adaptadas aos solos oligotróficos (Vilela \& Haridasan 1994), estas podem responder à aplicação de cálcio e à adubação no solo, elevando a concentração dos nutrientes na biomassa de seus órgãos aéreos. Por outro lado, Carvalho et al. (1998) notaram um possível efeito negativo da adubação com N, P e K na biomassa de $V$. herbacea, porém, não tendo encontrado diferenças significativas dado o elevado coeficiente de variação das medidas de crescimento.

Trabalhando com Achyrocline alata, outra Asteraceae do cerrado, Haridasan et al. (1997) verifi- 

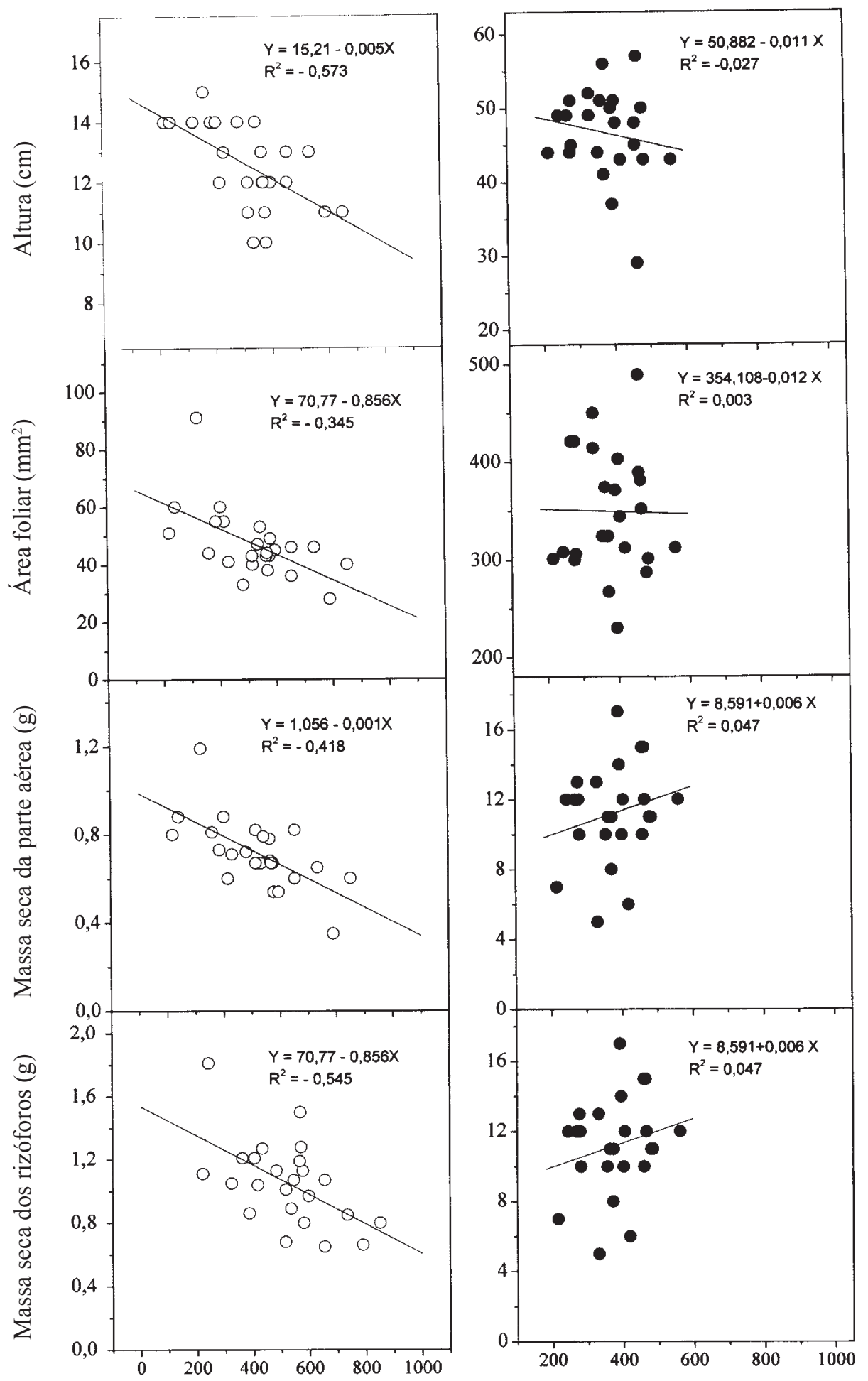

Concentração de frutanos $\left(\mathrm{mg} \mathrm{g}^{-1} \mathrm{~ms}\right)$

Figura 3. Correlação entre a concentração de frutanos e medidas de crescimento em plantas de Vernonia herbacea após 6 meses $(\bigcirc)$ e 12 meses $(\bullet)$ de cultivo em uma área de cerrado.

Figure 3. Correlation between fructan concentration and plant growth in Vernonia herbacea cultivated in a cerrado area for 6 $(\bigcirc)$ and $12(\bullet)$ months. 


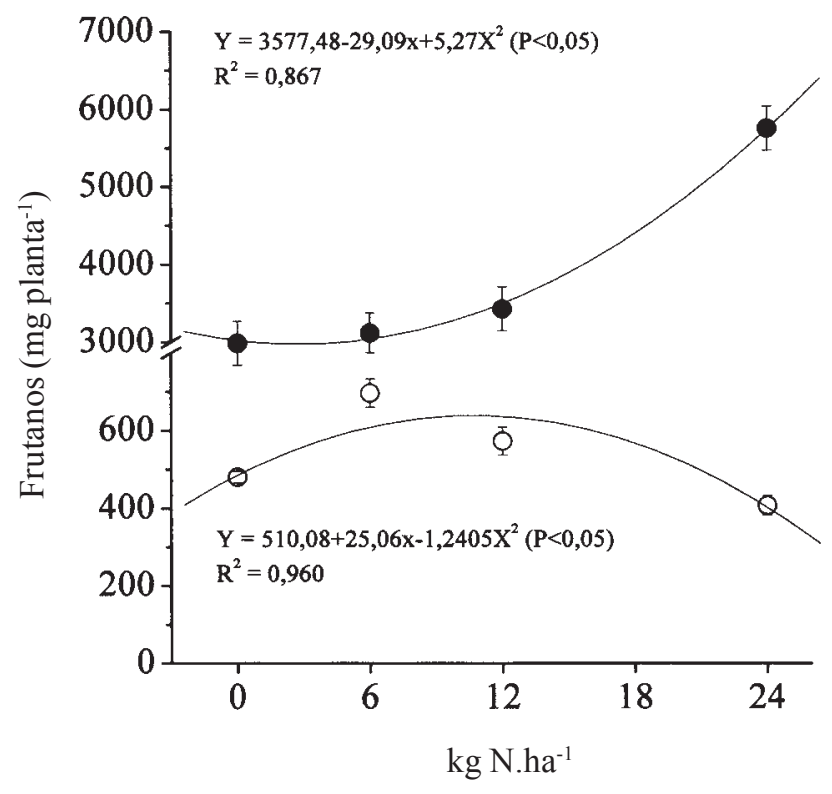

Figura 4. Efeito de diferentes níveis de adubação nitrogenada na produção de frutanos por planta de Vernonia herbacea após 6 meses $(\bigcirc)$ e 12 meses $(\bullet)$ de cultivo em uma área de cerrado. Barras representam erro padrão $(n=6)$.

Figure 4. Effect of different nitrogen concentrations on fructan production of Vernonia herbacea cultivated in a cerrado area for $6(\bigcirc)$ and $12(\bullet)$ months. Bars represent standard error $(n=6)$.

caram que a adição crescente de cálcio no solo causou um aumento de até $87 \%$ na concentração de Ca na parte aérea das plantas. No entanto, outras espécies de cerrado apresentaram respostas positivas ao $\mathrm{P}$ e ao $\mathrm{K}$, mas não ao N. Nesse aspecto, Felippe \& Dale (1990) constataram aumento na área foliar e biomassa seca de Bidens gardneri, uma Asteraceae do cerrado, em resposta às doses crescentes do $\mathrm{P}$, atingindo valor máximo em 6 $\mathrm{mg}$ de $\mathrm{P}$ por planta, superior ao observado naturalmente em solos do cerrado.

Em algumas situações, os elementos fornecidos isoladamente não são capazes de promover qualquer acréscimo de biomassa, sendo necessária a combinação dos elementos para manifestar uma resposta satisfatória de crescimento. Nicoloso et al. (1999) verificaram que o $\mathrm{N}$ só apresentou efeito positivo sobre o crescimento quando combinado a outros elementos químicos. As interações entre os nutrientes são complexas e encontram-se bem documentadas para espécies cultivadas (Marschner 1995), mas são pouco estudadas em espécies selvagens. Portanto, estudos sobre o efeito da combinação de nutrientes podem otimizar a produção de biomassa em plantas de $V$. herbacea e, conseqüentemente, a produção de frutanos.

A adubação nitrogenada em $V$. herbacea alterou a partição de biomassa entre parte aérea e subterrânea. Nas plantas com 12 meses sob tratamento com $6 \mathrm{~kg} \mathrm{~N} . \mathrm{ha}^{-1}$, houve diminuição da produção da parte subterrânea em relação à parte aérea, quando comparada ao controle. Efeito similar foi observado por Renó et al. (1997), Melo (1999) e Oliveira (1999) em espécies arbóreas do cerrado adubadas com nitrogênio, mostrando que, de modo geral, a maior disponibilidade de $\mathrm{N}$ estimula a partição de biomassa para os órgãos aéreos, aumentando a razão parte aérea:parte subterrânea. No entanto, essa razão pode variar muito entre as espécies e nas diferentes fases do seu ciclo de vida (Oliveira 1999). Em $V$. herbacea, a razão parte aérea:parte subterrânea aumenta na primavera e verão, coincidindo com a fase de crescimento vegetativo e de florescimento e, no final do outono, quando as plantas entram na fase de senescência, essa razão diminui (Carvalho et al. 1997).

Em estudos do comportamento nutricional, a fase do desenvolvimento vegetal pode interferir nas respostas aos tratamentos, uma vez que as exigências nutricionais podem variar com a idade da planta (Marschner 1995). Plantas jovens de V. herbacea responderam progressivamente às doses crescentes de adubação nitrogenada, enquanto em plantas com 12 meses de idade, respostas positivas ocorreram apenas nas doses entre 6 e $12 \mathrm{~kg} \cdot$ ha $^{-1}$ de nitrogênio (figura 1). Tais resultados são consistentes com aqueles obtidos por Collins \& McCoy (1997) que constataram diferentes respostas quanto à produção de raízes tuberosas de C. intybus em função da idade das plantas. Nesse estudo, plantas de $C$. intybus com um ano mostraram resposta linear crescente ao aumento das doses do nitrogênio e plantas com dois anos apresentaram dois tipos de respostas: linear crescente e quadrática crescente, com um ponto máximo na dose de $150 \mathrm{~kg} \mathrm{ha}^{-1}$ de nitrogênio. No caso do cerrado, esta maior exigência observada em plantas jovens de $V$. herbacea pode ter importante papel ecológico no sentido de limitar a população de plantas adultas evitando que o cerrado se transforme em uma vegetação mais densa (Melo 1999).

A adubação nitrogenada em plantas com seis e 12 meses de idade resultou em respostas diferentes não apenas no crescimento, mas também no conteúdo de frutanos. Doses crescentes de adubação nitrogenada causaram decréscimo na concentração de frutanos em plantas jovens, ao passo que efeito contrário ocorreu em plantas com 12 meses de idade (figura 2). No 
6 meses
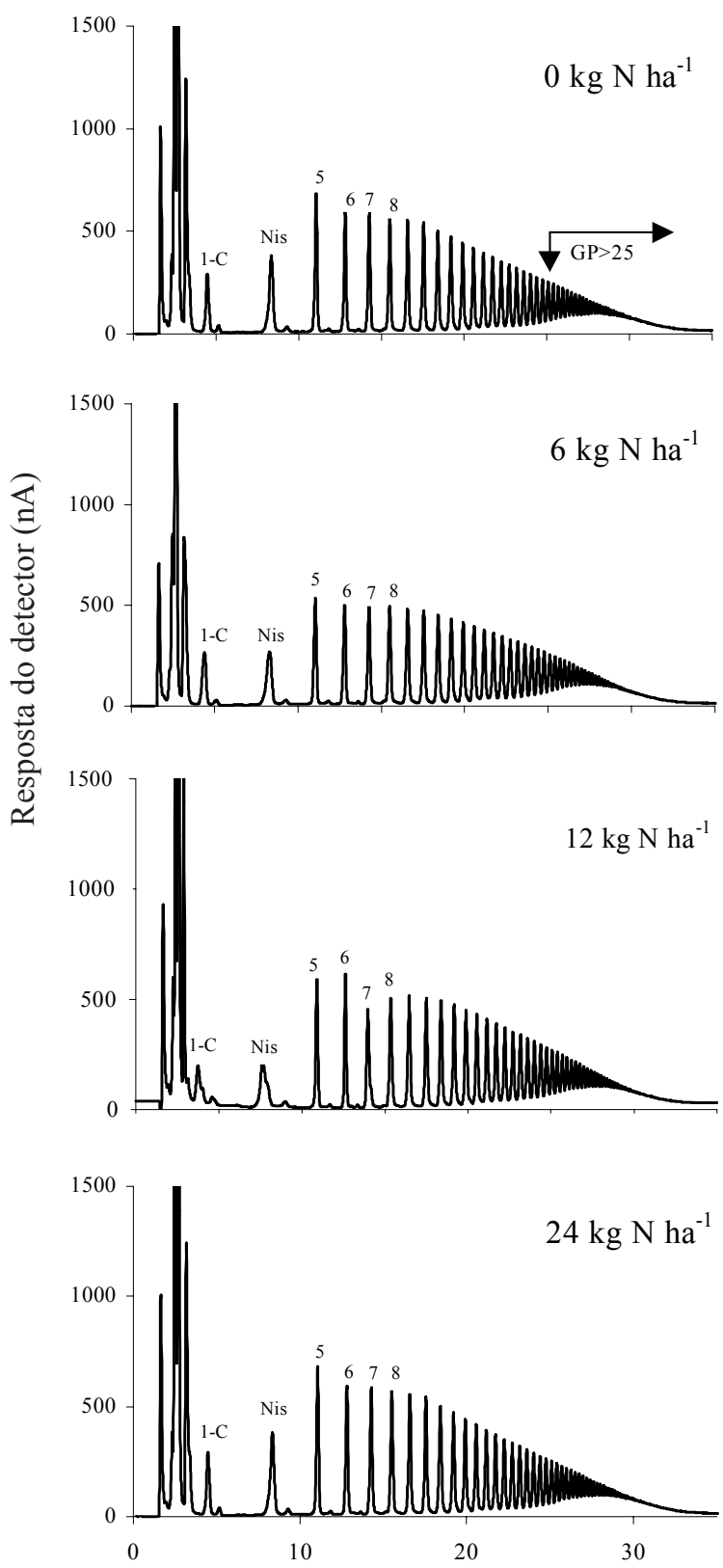

12 meses
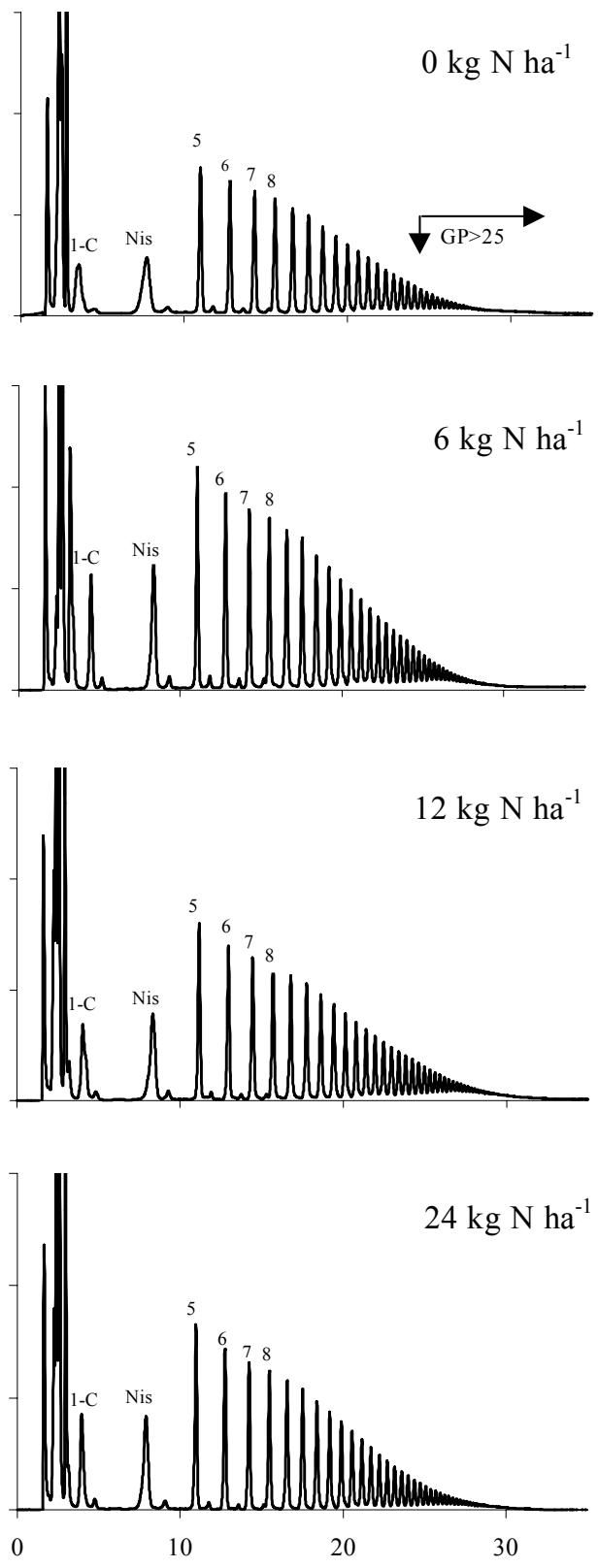

Tempo de retenção (min)

Figura 5. Análise por cromatografia de troca aniônica de alta resolução dos frutanos de rizóforos de plantas de Vernonia herbacea cultivadas em diferentes níveis de adubação nitrogenada, após 6 e 12 meses de cultivo em uma área de cerrado. Foram aplicadas amostras contendo concentrações equivalentes de frutose total. 1-C: 1-cestose, nis: nistose, numerais 5 a 8 referem-se aos fruto-oligossacarídeos com graus de polimerização de 5 a 8 . Os picos menores alternados com os da série principal de frutanos correspondem aos componentes da série da inulo- $n$-ose.

Figure 5. High performance anion exchange chromatography of fructans from rhizophores of Vernonia herbacea cultivated in a cerrado area, under different nitrogen concentrations for 6 and 12 months. Samples contain equivalent fructose concentrations. 1-C: 1-kestose, nis: nystose, numerals 5 to 8 refer to fructo-oligosaccharides with degrees of polymerization from 5 to 8 . The smaller peaks intercalated with those of the inulin series correspond to components of the inulo- $n$-ose series. 
entanto, esses resultados não permitem afirmar que a síntese de frutanos esteja sob controle direto da fertilidade do solo, uma vez que diferentes respostas ocorreram em função da idade das plantas e das épocas de avaliação (outubro e abril). Correlação negativa entre crescimento e concentração de frutanos foi constatada em plantas jovens mas não em plantas com 12 meses de idade (figura 3). Outros estudos realizados com Asteraceae acumuladoras de frutanos, como H. tuberosus (Schittenhelm 1999), C. intybus (Van den Ende et al. 1999), Polymnia sonchifolia (Tsukihashi et al. 1991) e V. herbacea (Teixeira et al. 1997, Carvalho et al. 1998), também mostraram que o nitrogênio promoveu o crescimento vegetal em detrimento da concentração de carboidratos. Esses resultados reforçam a hipótese de que tratamentos que limitam o crescimento da planta proporcionam aumento no conteúdo de carboidratos de reserva (Pollock \& Jones 1986).

Quanto à época do ano, esperava-se que plantas colhidas em abril (12 meses de cultivo) mostrassem maior concentração de frutanos em relação às colhidas em outubro (seis meses de cultivo), uma vez que o conteúdo em frutanos de $V$. herbacea alcança valores mais elevados no outono (Carvalho \& Dietrich 1993). No entanto, isso não ocorreu, sugerindo que outros fatores, como a idade da planta, tenham influenciado a concentração de frutanos.

Excluindo a maior dose de nitrogênio, a capacidade de síntese de frutanos parece ter sido influenciada pela idade da planta, visto que plantas jovens mostraram maior concentração de frutanos em relação às plantas colhidas aos 12 meses de cultivo (figura 2). Analisando duas épocas de colheita, Carvalho et al. (1998) constataram comportamento similar, também em $V$. herbacea, tendo as plantas com dois anos apresentado menor concentração de frutanos do que plantas com um ano.

Aos 12 meses de cultivo, as proporções dos componentes da série homóloga de frutanos foram alteradas em resposta à adubação nitrogenada. Aumento de 1-cestose, nistose e oligômeros com GP 5-8 foi observado em rizóforos de plantas adubadas com $6 \mathrm{~kg} \mathrm{~N}$.ha-1. Quando comparadas às plantas com seis meses, plantas com 12 meses de idade mostraram diminuição nos fruto-polissacarídeos de GP $>25$ e aumento nos fruto-oligossacarídeos (figura 5), sugerindo maior atividade de hidrólise de frutanos em plantas mais desenvolvidas, caracterizadas pelas maiores medidas de crescimento (figura 1). A maior proporção dos componentes da série da inulo- $n$-ose em plantas com 12 meses, especialmente no tratamento de $6 \mathrm{~kg} \mathrm{~N}$.ha ${ }^{-1}$, confirmam essa hipótese, uma vez que essa série de frutanos é considerada produto de hidrólise de frutanos (Ernst et al. 1996). Em H. tuberosus e C. intybus também se verificou que o crescimento induzido por condições ambientais satisfatórias foi acompanhado pela diminuição na proporção de frutanos de cadeia longa em relação aos frutanos de cadeia curta, indicando que a degradação dos fruto-polissacarídeos ocorre durante a mobilização das reservas para atender à demanda da parte aérea (Jefford \& Edelman 1963, Van den Ende et al. 1999). Da mesma forma, Carvalho et al. (1998) notaram uma diminuição nos frutopolissacarídeos de GP $>8$ em relação aos frutooligossacarídeos (GP 3-8) em plantas de V. herbacea com dois anos de cultivo sob adubação mineral.

Os resultados obtidos mostraram que plantas adubadas com $24 \mathrm{~kg} \mathrm{~N} \cdot \mathrm{ha}^{-1}$ chegaram a acumular $6,0 \mathrm{~g}$ de frutanos por planta, enquanto em plantas não adubadas esse valor foi de $3,5 \mathrm{~g}$ (figura 4), o que representa um acréscimo de $70 \%$ na produtividade. A produção de frutanos estimada por área foi de, aproximadamente, $0,5 \mathrm{t}^{\text {ha }} \mathrm{h}^{-1}$ para plantas colhidas com um ano e tratadas com $24 \mathrm{~kg} \mathrm{~N} \cdot \mathrm{ha}^{-1}$. Carvalho et al. (1998) observaram que plantas com um ano de idade acumularam 1,9 $\mathrm{g}$ de frutanos por planta, chegando ao valor de 6,9 $\mathrm{g}$ apenas aos dois anos de idade. Portanto, a aplicação de $24 \mathrm{~kg} \mathrm{~N}$.ha ${ }^{-1}$ foi eficiente para promover a produção de frutanos, com redução do tempo de cultivo.

Concluindo, a adubação nitrogenada aparentemente estimulou o desenvolvimento das plantas de $V$. herbacea nos primeiros seis meses de cultivo, em detrimento do acúmulo de frutanos. Contudo, ao final dos seis meses seguintes, verificouse comportamento inverso, ou seja, aumento na concentração de frutanos nos rizóforos em detrimento do desenvolvimento vegetativo das plantas. Assim, a adubação nitrogenada em cobertura foi eficiente para aumentar a produtividade em uma colheita antecipada (12 meses), sem alterar de forma expressiva a composição dos frutanos.

Agradecimentos - À Fapesp, pelo apoio financeiro (Biotasp Proc. 98/05124-8), ao CNPq, pelas bolsas de Produtividade em Pesquisa de M.A.M Carvalho, C.J. Barbedo e L.B.P. Zaidan e à Capes (PICDT 23068.000024/99-20) pela concessão de bolsa de doutorado a G.R.F. Cuzzuol. 


\section{Referências bibliográficas}

BACON, J.S.D. \& LOXLEY, R. 1952. Seasonal changes in the carbohydrates of the Jerusalem artichoke tuber. Biochemical Journal 51:208-213

BHATIA, I.S., MANN, S.K. \& SINGH, R. 1974. Biochemical changes in the water soluble carbohydrates during the development of chicory (Cichorium intybus L.) roots. Journal of Science, Food and Agriculture 25:535-539.

CARVALHO, M.A.M \& DIETRICH, S.M.C. 1993. Variation in fructan content in the undergound organs of Vernonia herbacea (Vell.) Rusby at different phenological phases. New Phytologist 123:735-740.

CARVALHO, M.A.M., ZAIDAN, L.B.P. \& DIETRICH, S.M.C. 1997. Growth and fructan content of plants of Vernonia herbacea (Asteraceae) regenerated from rhizophores. New Phytologist 136:153-161.

CARVALHO, M.A.M., PINTO, M.M. \& FIGUEIREDORIBEIRO, R.C.L. 1998. Inulin production by Vernonia herbacea as influenced by mineral fertilization and time of harvest. Revista Brasileira de Botânica 21:275-280

COLLINS, M. \& MCCOY, E.J. 1997. Chicory productivity, forage quality, and response to nitrogen fertilization. Agronomy Journal 89:323-238.

COUSSEMENT, P. \& FRANCK, A. 1998. New food applications for inulin. Agro-food-Industry Hi-Tech 9:26-28.

ERNST, M., CHATTERTON, N.J. \& HARRISON, P.A. 1996. Purification and characterization of a new fructan series from species of Asteraceae. New Phytologist 132:63-66.

FELIPPE, G.M. \& DALE, J.E. 1990. The effects of phosphate supply on growth of plants from the Brazilian cerrado: experiments with seedlings of the annual weed, Bidens gardneri Baker (Compositae) and the tree, Qualea grandiflora Mart. (Vochysiaceae). Oecologia 82:81-86.

HARIDASAN, M., PINHEIRO, A.A.M.C. \& TORRES, F.R.R. 1997. Resposta de algumas espécies do estrato rasteiro de um cerrado à calagem e à adubação. In Contribuição ao conhecimento ecológico do cerrado (L.L. Leite \& C.H. Saito, eds.). Embrapa, Brasília, p.87-91.

HIDAKA, H. \& HIRAYAMA, M. 1991. Useful characteristics and commercial applications of fructo-oligosaccharides. Biochemical Society Transactions 19:561-565.

ISEJIMA, E.M. \& FIGUEIREDO-RIBEIRO, R.C.L. 1993. Fructan variation in tuberous roots of Viguiera discolor Baker (Asteraceae): the influence of phenology. Plant and Cell Physiology 34:723-727.

JEFFORD, T.G. \& EDELMAN, J. 1963. The metabolism of fructose polymers in plants. 2. Effect of temperature on the carbohydrate changes and morphology of stored tubers of Helianthus tuberosus L. Journal of Experimental Botany 14:56-62.

JERMYN, M.A. 1956. A new method for the determination of ketohexoses in presence of aldohexoses. Nature 177:38-39.
MARSCHNER, H. 1995. Mineral nutrition of higher plants. Academic Press, Orlando.

MEIJER, W.J.M., MATHIJSSEN, E.W.J.M. \& BORM, G.E.L. 1993. Crop characteristics and inulin production of Jerusalem artichoke and chicory. In Inulin and inulin containing crops, Studies in Plant Science (H. Fuchs, ed.), Elsevier, Amsterdam, p.29-38.

MELO, J.T. 1999. Respostas de espécies arbóreas do cerrado a nutrientes em latossolo vermelho escuro. Tese de doutorado, Universidade de Brasília, Brasília.

MORAES, D.D.A. 1994. Resposta de algumas espécies arbóreas nativas do cerrado à adubação e calagem. Dissertação de mestrado, Universidade de Brasília, Brasília.

NICOLOSO, F.T., FOGAÇA, M.A.F., ZANCHETTI, F., MISSIO, E.L. \& FORTUNATO, R.P. 1999. Exigências nutricionais da grápia (Apuleia leicarpa (Vog.) Macbride) em solo podzólico vermelho amarelo - níveis de nitrogênio, fósforo e potássio. Revista Brasileira de Fisiologia Vegetal 11:157-159.

NILSSON, U., ÖSTE, R., JÄGERSTAD, M. \& BIRKHED, D. 1988. Cereal fructans: in vitro and in vivo studies on availability in rat and humans. The Journal of Nutrition 118:1325-1330.

OLIVEIRA, M.E. 1999. Influência de árvores das espécies nativas Dipteryx alata Vog. e Caryocar brasiliense Camb. no sistema solo-planta em pastagem de Brachiaria decumbens Stapf no cerrado. Tese de doutorado, Universidade de Brasília, Brasília.

POLLOCK, C.J. \& CAIRNS, A.J. 1991. Fructan metabolism in grasses and cereals. Annual Review of Plant Physiology and Plant Molecular Biology 42:77-101.

POLLOCK, C.J. \& JONES, T. 1986. Seasonal patterns of fructan and metabolism in forage grasses. New Phytologist 83:8-15.

POLLOCK, C.J., CAIRNS, A.J., SIMS, I.M. \& HOUSLEY, T.L. 1996. Fructans as reserve carbohydrates in crop plants. In Photoassimilate distribution in plants and crops: source-sink relationships (E. Zamski \& A.A.Shaffer, eds.). Marcel Dekker Inc, New York, p.97-113.

RENÓ, N.B., SIQUEIRA, J.O., CURI, N. \& VALE, F.R. 1997. Limitações nutricionais ao crescimento inicial de quatro espécies arbóreas nativas em Latossolo VermelhoAmarelo. Pesquisa Agropecuária Brasileira 32:17-25.

SCHITTENHELM, S. 1999. Agronomic performance of root chicory, Jerusalem artichoke, and sugarbeet in stress and nonstress environments. Crop Science 39:1815-1823.

SHIOMI, N. 1993. Structure of fructopolysaccharide (Asparagosin) from roots of asparagus (Asparagus officinalis L.). New Phytologist 123:263-270.

TEIXEIRA, P.G., CARVALHO, M.A.M, ZAIDAN, L.B.P. \& KLEIN, A.L. 1997. Effect of mineral nutrients on growth and fructan contents in plants of Vernonia herbacea. Revista Brasileira de Fisiologia Vegetal 9:89-96.

TOMOMATSU, H. 1994. Health effects of oligosaccharides. Food Technology 48:61-65. 
TSUKINHASHI, T., ASAMI, T., MINASAWA, K. \& KUBOTA, M. 1991. Effect of nitrogen and potassium fertilizer on the growth and yield of yacon (Polymnia sonchifolia). Vocacional Agriculture 38:50-56.

VAN DEN ENDE, W., DE ROOVER, J. \& VAN LAERE, A. 1999. Effect of nitrogen concentration on fructan and fructan metabolizing enzymes in young chicory plants (Cichorium intybus). Physiologia Plantarum 105:2-8.
VIEIRA, C.J. \& FIGUEIREDO-RIBEIRO, R.C.L. 1993. Fructose-containing carbohydrates in the tuberous root of Gomphrena macrocephala St.-Hil. (Amaranthaceae) at different phenological phases. Plant, Cell and Environment 16:919-928.

VILELA, D.M.V. \& HARIDASAN, M. 1994. Response of the ground layer community of a cerrado vegetation in central Brazil to limiting and irrigation. Plant and Soil 163:25-31. 